\title{
CAÍDOS POR DIOS Y POR ESPAÑA. EL CULTO A LA MUERTE EN LA FUNDACIÓN DE LA DICTADURA FRANQUISTA
}

\section{FALLEN FOR GOD AND FOR SPAIN. THE CULT OF DEATH IN THE FOUNDATION OF THE FRANCO'S DICTATORSHIP}

\author{
Francisco Sevillano-Calero \\ Universidad de Alicante (España) \\ orcid.org/0000-0001-8550-8978
}

Recibido el 20-7-2016 y aceptado el 22-11-2016

Resumen: Este artículo analiza como la legitimación del «nuevo Estado» en España se fundó sobre el mismo evento de la guerra desde el verano de 1936. La propagación de las representaciones de la guerra formó una cultura de guerra, constitutiva de la identidad colectiva en la «España nacional», opuesta a la anti-España. Como sucedió a través de la institucionalización del culto de la muerte, la transferencia de elementos dogmáticos, litúrgicos y rituales del cristianismo a la política fue esencial en la construcción de esa cultura de guerra.

Palabras clave: Guerra Civil española, cultura de guerra, culto a la muerte, propaganda, lugares de memoria.

\footnotetext{
Abstract: This paper studies the collective memory of the war in Spain from July 1936 through the mourning the «fallen» in defense of «national cause». The practice of public mourning occurred within the traditional framework of the Catholic Church. The organization of mourning as a representation of the war culture in time and space sacred by Falange Española Tradicionalista de las JONS through a peculiar rhetoric, the festive calendar, the ceremonials, and the monuments and memorials, as in Paracuellos del Jarama, made inevitable the tensions in the Francoist «new State».
}

Keywords: Spanish Civil war, Franco's regime, war culture, mourning, propaganda. 
El final de la guerra de España, que proclamó el último parte del Cuartel General Militar del «Generalísimo» Francisco Franco en la noche del 1 de abril de 1939, día de Sábado Santo, hizo inmediatamente presente el dolor y el duelo de la experiencia traumática de la muerte masiva $^{1}$. La política del recuerdo en la España de posguerra instauró el culto a la muerte como parte del universo simbólico del «nuevo Estado» ${ }^{2}$. Esta política cultual fue un elemento de la «cultura de guerra» que caracterizó la fundación de la dictadura franquista, contribuyendo con sus valores, ideas, símbolos y ritos a formar una persistente trama de significación que legitimó el «Alzamiento» y la lucha en la «Cruzada» contra la anti-España en defensa de la patria ${ }^{3}$. En esta trama de significación, el culto a los «caídos» adoptó las ideas escatológicas cristianas de muerte, salvación y resurrección. Pero su significado profundo estuvo a distancia de la referencia inmediata de la teología política del nacional-catolicismo. En esencia, el culto a los «caídos» fue inicialmente una forma de sacralización de la política y de la violencia en la «nueva España». Pro Patria Mori, el morir por la patria como sacrificio, fue vivido colectivamente como comunión espiritual con el corpus mysticum de la nación: la «violencia sagrada» del sacrificio fue percibida como el origen fundador de la comunidad nacio$\mathrm{nal}^{4}$.

1 Además de los trabajos de G. Gorer, Ph. Ariès o M. Vovelle que se sucedieron entre 1966 y 1975 sobre las actitudes ante la muerte en Occidente, véase la crítica a la idea de la «muerte invertida», es decir, del nacimiento del tabú de la muerte en el siglo Xx que sostienen tales autores (sobre todo en el ensayo de Gorer, 1955, pp. 49-52), en Cannadine, 1981, pp. 187-242.

2 A partir del libro de Winter, 1995, se han sucedido y multiplicado los estudios sobre el duelo colectivo y la construcción y el uso político de la memoria de los muertos, sobre todo tras la Gran Guerra. Además del trabajo pionero de Paul Fussell, véanse Mosse, 1991 (trad. esp.: Mosse, 2016); Gregory, 1994; Sherman, 1999, así como las contribuciones reunidas en Winter y Sivan, 1999. Véase, para el caso de España, Ledesma y Rodrigo, 2006, pp. 233-255.

3 Acerca de la noción de «cultura de guerra» en relación con la Gran Guerra en Francia, véanse las precisiones que hicieron Becker y Audoin-Rouzeau, 1994, pp. 5-7, Becker y Audoin-Rouzeau, 1997, pp. 251-271, y Becker y Audoin-Rouzeau, 2000. Este enfoque de historia cultural de la guerra asumió la propuesta interpretativa que el historiador George L. Mosse hizo sobre la «brutalización» de la política en la Alemania de posguerra.

${ }^{4}$ Acerca del temprano desarrollo de la idea Pro Patria Mori dentro de los conceptos del mundo cristiano medieval, y su herencia en la contemporaneidad, véase Kantorowicz, 1951, pp. 472-492. Respecto a la vivencia religiosa de la Gran Guerra en Francia que, ante la presencia de la muerte en semejante situación extraordinaria, dio una carga inhabitual a toda la aprehensión de lo divino, véase Becker, 1994. 
La institucionalización de este culto ocurrió durante la exaltación ceremonial de la «Victoria» en el año 1939. La tesis de este artículo es que pueden distinguirse, en el proceso de fundación cultual, distintos procedimientos, que fueron sucediéndose, pero siempre de modo acumulativo y estrechamente unidos. Así, puede especificarse: 1. La politización del recuerdo colectivo de los «caídos», 2. La ritualización y la retórica de la muerte traumática, y 3. La «localización» del recuerdo de los «caídos». Conforme quedó institucionalizado a principios de 1940, este culto persistió en las décadas siguientes. La conmemoración del vigésimo aniversario del final de la guerra en España el 1 de abril de 1959, que culminó con la inauguración del Valle de los Caídos, renovó el culto a la muerte, si bien conllevó un cambio sustancial por la construcción de una «memoria cultural» a partir del recuerdo de la guerra como origen primordial de la «nueva España». En la base de este proceso, el concepto de «memoria cultural» permite comprender el sentido de la política cultual durante la dictadura franquista, pues la memoria cultural se caracteriza por su distanciamiento de lo cotidiano y de la inmediata comunicación interpersonal, arraigando en lo originario, que es un punto fijo en el pasado; un horizonte temporal que no se desvanece con el paso del tiempo ${ }^{5}$.

\section{La politización del recuerdo colectivo de los «caídos»}

El 16 de abril, el papa Pío XII expresó radiofónicamente a los católicos españoles su congratulación por «el don de la paz y de la victoria, con que Dios se ha designado coronar el heroísmo cristiano de vuestra fe y caridad, probado en tantos y tan generosos sufrimientos ${ }^{6}$. En el mensaje, manifestó sus halagüeñas esperanzas de que el camino de la tradicional y católica grandeza de España había de ser el norte que orientara a todos los españoles, amantes de su religión y su patria, en el esfuerzo de organizar la vida de la nación en perfecta consonancia con su nobilísima historia

${ }^{5}$ El concepto de «memoria cultural» fue establecido por Aleida y Jan Assmann, trascendiendo la noción de mémoire collective de Maurice Halbwachs. Véase Assmann, 2005, pp. 6583, noción que ya había desarrollado en uno de sus principales trabajos: Assmann, 1992.

6 «A SSMO D. N. Pio Div. Prov. Papa XII ad universos hispaniae christifideles datus, die XVI mensis Aprilis, anno MCMXXXIX», Acta Apostolicae Sedis. Comentarium Officiale (AAS), Annus XXXI, Series II, Vol. VI, Typis Polyglottis Vaticanis, Romae, 1939, p. 151 . 
de fe, piedad y civilización católicas. El papa Pío XII no olvidó reverenciar la memoria de los mártires que habían muerto por su fe y amor a la religión católica ${ }^{7}$. En la política de pacificación, el episcopado tenía que aconsejar a todos que siguiesen los principios inculcados por la Iglesia y proclamados por el «Generalísimo» Francisco Franco: justicia para el crimen y benévola generosidad con los equivocados. No había que olvidar a quienes habían sido engañados por una propaganda mentirosa y perversa, conduciéndoles nuevamente con paciencia y mansedumbre al seno regenerador de la Iglesia y al tierno regazo de la patria ${ }^{8}$.

En la inmediata posguerra, la jerarquía eclesiástica española se ocupó de la rehabilitación del recuerdo de los «mártires» de la Iglesia. Ello ocupó la consideración de la Conferencia de Metropolitanos españoles. En la reunión que se celebró en Toledo, presidida por el Cardenal Isidro Gomá, Arzobispo Primado de esa capital, los días 2 a 5 de mayo de 1939, fueron varios los acuerdos que se tomaron para la ejecución de los que se habían adoptado en la conferencia de noviembre de 1937, para cuando acabara la guerra. En primer lugar, se convino nombrar una comisión que se encargase de recoger todo el material posible que ofreciera los datos fehacientes para la historia de la persecución que la Iglesia había padecido en España durante aquellos últimos años, particularmente «con fines de apologética y de glorificación de nuestros mártires y singularmente de los obispos y sacerdotes». Fundamentalmente podrían servir los cuestionarios remitidos o que se enviaran a las últimas diócesis que habían sido «liberadas». Fruto de los trabajos de la comisión, podría ser la publicación de uno o varios folletos o libros sobre la naturaleza, extensión y magnitud de la persecución sufrida por la Iglesia en España y sobre el número y la magnificencia de sus mártires. Otro resultado especial sería la publicación de un libro de síntesis sobre la historia de la catástrofe que había sufrido la Iglesia española, añadiendo a la parte histórica el estudio de sus causas morales y sociales. Asimismo, y como tributo del episcopado a sus hermanos difuntos, podría publicarse una monografía sobre su historia y martirio. Por último, cada diócesis publicaría un opúsculo semejante dedicado a sus sacerdotes, seminaristas y religiosos martirizados ${ }^{9}$.

7 Ibidem, p. 153.

8 Ibidem, pp. 153-154.

9 «Acta de la Conferencia de Metropolitanos españoles celebrada los días 2-5 de mayo de 1939», en Actas de las Conferencias de Metropolitanos españoles (1921-1965), edición de Vicente Cárcel Ortí, BAC, Madrid, 1994, p. 403. 
Se acordó también el proponer a todos los prelados que, como homenaje a los eclesiásticos asesinados por los «marxistas», se celebrara un funeral solemne en todas las catedrales, iglesias parroquiales y conventuales. Asimismo se dispuso que se celebrase otro funeral por todos los españoles que habían sucumbido «por Dios y por España. La Conferencia propuso igualmente que se colocara, en el interior de las catedrales, una lápida en la que estuviesen inscritos los nombres de los sacerdotes asesinados, de las diócesis respectivas, figurando a la cabeza el del prelado, si hubiera sido asesinado también. Ello sin perjuicio de que se inscribieran, en sus respectivas parroquias, los nombres de los sacerdotes que allí ejercieron su ministerio. Además, donde hubiese constancia de que hubiera sucumbido algún sacerdote, si fuese un sitio público, se señalaría el lugar al menos con una cruz y una sencilla inscripción ${ }^{10}$. Estos acuerdos fueron una réplica a la disposición legal, por Decreto de 16 de noviembre de 1938, de que figurase una inscripción en los muros de cada parroquia con los nombres de los «caídos» durante la guerra.

De igual forma se decidió la celebración de funciones de desagravio a Dios, como reparación de los sacrilegios cometidos en España por la «revolución», en la forma que cada prelado ordenase para su diócesis, y se propuso que se hicieran en toda España durante la novena y fiesta del Sagrado Corazón de Jesús, dándoles solemnidad extraordinaria y fervor de expiación y penitencia. Además, se acordó que en el programa de fiestas anuales del Apóstol Santiago y en las extraordinarias que se preparaban para celebrar el centenario de la venida de la Virgen del Pilar a Zaragoza se incluyese algún acto de relevante carácter expiatorio ${ }^{11}$.

La restauración de la plenitud y autonomía de la esfera católica por las autoridades del «nuevo Estado» había hecho que, por Ley de la Jefatura del Estado de 10 de diciembre de $1938^{12}$, se restableciera la integridad, propiedad y jurisdicción eclesiástica en los cementerios parroquiales, poniendo fin a su secularización. La inflación de religiosidad individual y colectiva ante una situación extraordinaria, la guerra y la presencia y proximidad de la muerte traumática y masiva, llevó a recuperar la práctica de los enterramientos ad santos, o al menos dentro del espacio sagrado

\footnotetext{
10 Ibidem, pp. 403-404.

11 Ibidem, p. 404.

12 Boletín Oficial del Estado (BOE), 20-XII-1938.
} 
de los templos, criptas, casas religiosas o en los locales anejos a unos y otras $^{13}$.

Al margen de las competencias de la autoridad eclesiástica sobre los lugares sagrados, desde las instancias del «nuevo Estado» fue interviniéndose en el proceder, la circunspección y el homenaje con los «caídos» que habían entregado su vida en defensa de la «causa nacional». Por Ley de 16 de mayo de $1939^{14}$ se facultó a los ayuntamientos para dispensar o reducir las exacciones municipales que gravaban las inhumaciones, exhumaciones y traslados de los cadáveres de los «caídos» por la «barbarie roja» o en el frente; lo que fue justificado en el breve preámbulo de la Ley alegando que obedecía, en aquellos momentos, «a la verdadera necesidad de rendir el postrero homenaje de respeto a los restos queridos de personas asesinadas en circunstancias trágicas o muertas en el frente y cuyo enterramiento se ha verificado muchas veces en lugares inadecuados».

La necesidad de facilitar administrativamente a los familiares la recuperación, el traslado y el enterramiento de los cadáveres se conjugó con una decidida política del recuerdo de los «caídos», promovida bajo la jefatura del falangista Dionisio Ridruejo desde la Subsecretaría de Prensa y Propaganda. Con objeto de unificar el estilo y dar sentido a la perpetuación en un monumento de los hechos y las personas de la Historia de España, en especial para conmemorar la guerra y en honor a los «caídos», y de evitar que el entusiasmo pudiera prevalecer caprichosamente en estas iniciativas, provocando incluso la desilusión cuando se tratase de proyectos inviables, la Orden del Ministerio de la Gobernación de 7 de agosto de ese año estableció que todas las iniciativas de monumentos en general, e incluso la apertura de suscripciones para su construcción, concursos de proyectos, etc., quedaban supeditadas a la aprobación ministerial. Asimismo, se prohibió publicar noticias o informes, o hacer cualquiera otra clase de propaganda, sobre iniciativas y proyectos hasta que no se obtuviese la aprobación ministerial a través de la Jefatura del Servicio Nacional de Propaganda ${ }^{15}$.

13 Véase, al respecto, lo dispuesto en la Orden del Ministerio de 31 de octubre de 1938 (BOE, 3-XI-1938).

14 BOE, 17-V-1939.

15 BOE, 22-VIII-1939. Para la resolución de las peticiones que fueran elevadas, véase el procedimiento establecido en las circulares de 5 de octubre de ese año (AGA, SC, MIT, c. 1364) y de 16 del mismo mes de ese año (AGA, SC, MIT, c. 1378). La Orden de 30 de octubre de 1940 (BOE, 12-XI-1940), reguló la tramitación de los expedientes sobre iniciativas de conmemoraciones. 
Estas iniciativas para la recuperación y sepultura de los cuerpos de los muertos y la perpetuación de su recuerdo en monumentos conmemorativos avanzaron en el establecimiento del culto a los «caídos», ya presente fuera del tiempo litúrgico de la Iglesia católica a través del calendario de celebraciones del «nuevo Estado», que había ido implantándose desde julio de 1937. Un culto que exaltó y capitalizó sobre todo el partido único Falange Española Tradicionalista y de las JONS con motivo de la celebración del aniversario de la muerte y de los funerales José Antonio Primo de Rivera en noviembre de 1938 a través de toda la parafernalia de oraciones, voces y gestos que viniera empleando la Falange en el culto a sus «caídos» desde $1934^{16}$. El sacrificio de los «caídos», renovado ritualmente de modo periódico como un fenómeno religioso colectivo, es el medio para que lo profano pueda comunicarse con lo sagrado: la nación como comunidad imaginada ${ }^{17}$. Este exacerbado culto político nacionalista, y profano en algunas de sus manifestaciones, ocupó el espacio público, irrumpió en los lugares sagrados y se sirvió de los símbolos, los ritos y las celebraciones litúrgicas en el recuerdo de los «caídos». Ello provocó inmediatamente la reacción de la cúpula arzobispal de la Iglesia católica española ${ }^{18}$.

Que la Jefatura de Prensa resolviera prohibir la divulgación de la carta pastoral Lecciones de la guerra y deberes de la paz, redactada por el Cardenal Primado Gomá y Tomás con fecha de 8 de agosto de $1939^{19}$, evidenció las tensiones que estaban produciéndose por las políticas del «nuevo Estado», sobre todo bajo la hegemonía del proyecto falangista y por la influencia nazi. En su carta pastoral, el Cardenal Isidro Gomá afirmó que una lección altísima de la guerra era la fuerza religiosa del espíritu español, ejemplificada en el martirio: «Nos referimos al volumen imponderable del número, del heroísmo, de las formas inverosímiles de tormento, de paciencia invicta que nos ofrece el martirio de millares de

16 Véanse González Calleja y Sevillano Calero, 2003, pp. 89-113; Di Febo, 2006, pp. 189-202; y Box, 2005, pp. 191-218, y Box, 2009, pp. 265-298.

17 Sobre la concepción del sacrificio como línea delimitadora entre lo profano y lo sagrado, condición misma de la existencia divina, véase Hubert y Mauss, 1897-1898, pp. 29 138 (p. 130 y 133, especialmente). Véase la recopilación de este trabajo en Mauss,1970, pp. 143-262 (ed. or. en francés del mismo año).

18 Véase, al respecto, Lazo, 1998 y Lazo, 2014.

19 Véanse Rodríguez Aisa, 1981; Dionisio Vivas, 2009 y Dionisio Vivas, 2015. La carta pastoral fue publicada en el Boletín Oficial Eclesiástico del Arzobispado de Toledo, el 1 de septiembre de 1939, siendo reproducida en Goma y Tomás, 1940. Las siguientes citas proceden de esta edición. 
españoles sacrificados por su profesión de cristianos». Hasta el punto que, tal vez, lo que diese definitivamente su eficacia al Movimiento Nacional fuera el martirio que sufrió por Jesucristo un gran número de millares de católicos españoles, que como testigos eran prueba invicta del arraigo de la fe colectiva de todo un pueblo ${ }^{20}$.

Los deberes para con los muertos eran una obligación que quedaba cumplir en la paz, pues había que perpetuar «la memoria de los que sucumbieron por Dios y por la Patria»; todos los pueblos habían cumplido con esta deuda hacia quienes dieron sus vidas por esos dos grandes ideales, soporte de toda sociedad bien constituida. Pero el Cardenal Gomá expresó su pesar por ciertas formas de traducir este pensamiento y hecho universal ante la muerte que tal vez desdecían del pensamiento cristiano sobre Dios y patria, y hasta de la idea cristiana del heroísmo y de la muerte:

«Una llama que arde continuamente en un sitio público, ante la tumba convencional del «soldado desconocido», nos parece cosa bella, pero pagana. Es símbolo de la inmortalidad, de la gratitud inextinguible, de un ideal representado por la llama que sube, pero sin expresión de una idea sobrenatural. Un poema ditirámbico que se canta en loor de los "caídos", con pupilas de estrellas y séquito de luceros, es bellísima ficción poética, que no pasa de la categoría literaria: ¿Por qué no hablar el clásico lenguaje de la fe, que es a un tiempo el clásico lenguaje español?

Más cristiano es lo que hemos visto en las parroquias de Francia, en las que se ha esculpido en mármol el nombre de los feligreses que sucumbieron en la gran guerra, con los símbolos y fórmulas tradicionales de la plegaria cristiana por los difuntos: es una forma de memento que al par que fomenta el espíritu de parroquia, recuerda a la feligresía el heroísmo cristiano de sus muertos y el deber de dedicarles oraciones y sufragios $»^{21}$.

Para el futuro, la reforma personal mediante una mayor dignidad humana y cristiana había de oponerse a quienes identificaban el interés individual con el colectivo y a un estatismo exagerado, pues la acción del Estado sería externa y limitada ${ }^{22}$. La obligación fundamental en aquella

\footnotetext{
20 Ibidem, p. 247.

21 Ibidem, p. 268.

22 Ibidem, p. 270.
} 
posguerra era restituir a Dios en el sitio que le correspondía en el orden social $^{23}$. Para ello, había que dejar a la Iglesia en la absoluta libertad propia de su constitución y tenerla en el alto honor que reclama su origen divino y la gloriosa historia de su intervención en las sociedades ${ }^{24}$.

En la nota editorial «Un caso nuevo», que se publicó en el Boletín Oficial Eclesiástico del Arzobispado de Toledo, el 15 de septiembre de 1939, se señaló que tal caso novedoso era el que, en un Estado católico y por disposición gubernativa, se prohibiese «rigurosa y totalmente» la publicación de una carta pastoral de un prelado de la Iglesia, como había ocurrido con la publicada por el Cardenal Primado con el título de Lecciones de la guerra y deberes de la paz. En la nota se recordó la constante actuación del Cardenal Gomá en pro de la patria y los incontables servicios que había prestado al Estado en los últimos años, si bien no podía consentirse que quedasen sin defensa los fueros de la autoridad magistral de un prelado de la Iglesia ${ }^{25}$.

\section{La ritualización y la retórica de la muerte traumática}

La exaltación ritual y retórica de la muerte fue expresión de una hierofanía, es decir, una manifestación de lo sagrado en una realidad profana, avanzándose en la politización sesgada del recuerdo. El entierro con honores fúnebres del general Sanjurjo encuadró la celebración del 29 de octubre, día de los Caídos, en aquel «Año de la Victoria». Tras haber sido traslados sus restos mortales desde el cementerio portugués de Estoril ${ }^{26}$, el viernes 20 de octubre de ese año se dijeron misas sin interrupción desde las 8 de la mañana por el alma del difunto en la capilla ardiente instalada en la madrileña Estación de Mediodía, en la Puerta de Atocha ${ }^{27}$. Desde aquí se organizó la comitiva que trasladó los restos del general Sanjurjo

23 Ibidem, p. 272.

${ }^{24}$ Ibidem, p. 283.

25 Boletín Oficial Eclesiástico del Arzobispado de Toledo, 15-IX-1939. Aun estar firmado el editorial por la Dirección, fue redactado por el propio Cardenal Primado (véase Granados,1969, p. 233).

26 Por Decreto de 14 de septiembre de 1939 (BOE, 15-IX-1939), se había nombrado una comisión para asistir al traslado del cadáver del general Sanjurjo desde Lisboa.

${ }_{27}$ Ese mismo día, el general Franco firmó el Decreto concediendo el empleo de capitán general del Ejército español al teniente general José Sanjurjo Sacanell, con la antigüedad de 20 de julio de 1936 (BOE, 26-X-1939). 
por las calles de la capital hasta la Estación del Norte. El féretro fue llevado en un armón de Artillería, envuelto en la bandera nacional. El convoy, que partió desde esta segunda estación madrileña, fue recibido en acto de homenaje a pie de andén a su paso por las estaciones de Villalba, El Escorial, Ávila, Medina del Campo, Valladolid y Venta de Baños, adquiriendo los actos especial relevancia en Burgos (donde llegó la noche de ese viernes) y, tras su paso por Vitoria, en Pamplona, a lo largo de la tarde del sábado 21 de octubre y el domingo día 22.

El entierro del general Sanjurjo transcendía la persona del militar que muriera el 20 de julio de 1936 en accidente de avión al trasladarse desde Portugal para encabezar el golpe de Estado militar que había ocurrido en España. El periodista Francisco de Cossío subrayó, en el artículo «Un entierro histórico», que los restos mortales se hacían símbolo y, descendiendo de nuevo el espíritu, vivificaba cuanto el hombre muerto representó en la vida. El entierro de Sanjurjo era no sólo el homenaje que se debía a un héroe, sino el acto de adhesión profunda y grave que España debía a su Ejército. Apiñados en torno al féretro, iban todos los «caídos» por España, los supervivientes y héroes. Un acto que era estimado por el columnista del $A B C$ como un buen reactivo para los desmemoriados ${ }^{28}$.

El deber de recordar, sobre todo a los muertos anónimos cuyos cadáveres no habían sido recuperados, fue señalado también por Francisco de Cossío, a la sazón subdirector del diario $A B C$, el 28 de octubre, en el artículo «Los caminos sagrados» ${ }^{29}$. La hierofanía a través de la sangre derramada por los «caídos» en defensa de la patria revelaba el espacio sagrado de la tierra de España en cada uno de sus caminos - y no sólo en sus cementerios - en que yacían los muertos anónimos.

La retórica falangista elevó aún más el tono elegíaco en la conmemoración de los «caídos». En la portada del número de La Vanguardia Española de ese día 29 de octubre, una destaca cruz latina enmarcó la Oración por los Caídos, de Rafael Sánchez Mazas. Como escribió Jacinto Miquelarena en las páginas del mismo número del diario barcelonés, el grito «ipresente!» no había de convertirse en la fórmula de un rito sin calor, pues era la esencia misma de la «nueva España» y exigía cumplir con

${ }^{28}$ Francisco de Cossío, «Un entierro histórico», $A B C$, Madrid, 21-X-1939.

${ }^{29}$ Francisco de Cossío, «Los caminos sagrados», $A B C$, Madrid, 28-X-1939. Este artículo apareció publicado el mismo día en el periódico barcelonés La Vanguardia Española, p. 5 . 
el deber: «Los Caídos cumplieron con su deber y exigen que cumplamos con el nuestro» ${ }^{30}$.

La conmemoración anual de cada 29 de octubre introducía la existencia de los hombres en un tiempo sagrado; un tiempo mítico primordial, hecho presente nuevamente: la propia guerra. Pero la fiesta del 29 de octubre conmemoraba también el aniversario de la fundación de Falange Española por José Antonio Primo de Rivera en el Teatro de la Comedia de Madrid en 1933: el sacrificio de los «caídos» por Dios y por España, y el acontecimiento mismo de la guerra, tenían su origen en aquel acto fundacional. Se trató de una sesgada apropiación falangista del recuerdo colectivo.

El editorial de La Vanguardia Española del 29 de octubre de 1939 destacó aquel origen, que daba sentido al martirio de muchos antes y después del 18 de julio de 1936:

«Caídos por Dios y por España. Hoy hace seis años que José Antonio os trazó, con su mano de profeta y de precursor, el camino del martirio, al trazaros las normas para vuestra voluntad de servicio. ¡Caídos que asistíais al discurso fundacional de nuestra Falange! Muchos de vosotros sucumbisteis en la altiva intemperie de la primera hora; a otros os cupo mayor notoriedad en el sacrificio, aunque no mayor gloria en el mérito, porque el mérito de todos se iguala en la sublimidad del martirio común. Hoy hace seis años que la mano del maestro, del apóstol y del camarada os trazó la ruta por donde él mismo os había, como siempre, de acompañar» ${ }^{31}$.

Luis de Galinsoga, director del diario barcelonés, escribió, en su columna periódica «Los hombres y los días», que aquel acto fundacional fue germen del «nuevo Estado» ${ }^{32}$. El sacrificio de los «caídos» se había convertido en el mito central de la ideología del Movimiento, como el escritor Eduardo Marquina afirmó en otro artículo en el mismo diario barcelonés. No había otro modo de culto que vivir a imagen y semejanza de los «caídos», debiéndose confirmar y renovar los votos periódicamente en el aniversario ante la Cruz de los Caídos ${ }^{33}$.

\footnotetext{
30 Jacinto Miquelarena, «Están con nosotros», La Vanguardia Española, 29-X-1939.

31 «In hoc signo vinces», La Vanguardia Española, 29-X-1939.

32 Luis de Galinsoga, «Semilla y fruto», La Vanguardia Española, 29-X-1939.

33 Eduardo Marquina, «Renovación de votos», La Vanguardia Española, 29-X-1939.
} 
La apropiación del culto de la muerte por la Falange fue encarnada en la figura de José Antonio Primo de Rivera. El editorial de Arriba de aquel 29 de octubre de 1939 destacó su santidad por el sacrificio de su muerte el 20 de noviembre de 1936 y por su entrega voluntariamente aceptada a la causa de España en el acto de fundación del partido ${ }^{34}$. Desde el día 19 de noviembre de 1939, el culto del «Ausente» alcanzó su mayor exaltación en el ritual de traslado de los restos mortales de José Antonio a hombros de militantes falangistas con todo el ceremonial y la parafernalia por carreteras y pueblos desde la ciudad de Alicante (donde fuera juzgado, fusilado y enterrado en una fosa común) hasta el Monasterio de San Lorenzo de El Escorial.

\section{La «localización» del recuerdo de los «caídos»}

El proceso de culto a la muerte en la inmediata posguerra se completó, tras la sepultura del cadáver de José Antonio Primo de Rivera, con la localización del recuerdo a los «caídos», es decir, señalando y delimitando los emplazamientos que debían acoger los restos mortales de los «caídos» a modo de «lugares de memoria» ${ }^{35}$. Es un tercer momento en la politización del recuerdo, en el que el culto a los «caídos», materializado en las tumbas y los cementerios, revela que la experiencia ritual del espacio sagrado permite obtener un «punto fijo» que funda el mundo, vivir realmente el pasado en el presente y orientar la acción futura. El lugar de Paracuellos de Jarama fue situado en el centro de la política del recuerdo del «nuevo Estado».

Por Decreto de 3 de febrero de $1940^{36}$ se concedieron honores de capitán general, con mando en plaza, a los restos de los españoles asesinados en Torrejón de Ardoz. Con anterioridad, desde el día 7 hasta el 20 de diciembre de 1939, la Asociación de Familiares había llevado a cabo la exhumación de restos mortales en ese término municipal, siendo recuperados 414 cadáveres, de los que se lograron identificar $64^{37}$. En el acto de

34 Arriba. Organo de Falange Española Tradicionalista y de las J.O.N.S. de Madrid, 29-X-1939, p. 1.

${ }^{35}$ La idea de la asociación de una idea a un lugar, transformado simbólicamente en un locus memoriae, fue expuesta en Nora, 1997, vol. 1, pp. 23-43.

36 BOE, 6-II-1940.

37 Archivo Histórico Nacional (AHN), Fondos Contemporáneos (FC), Causa General (CG), Pieza especial de Madrid sobre Exhumaciones de Mártires de la Cruzada, 1. 1536, exp. 2 . 
homenaje celebrado el 18 de febrero de 1940, seis cadáveres, a los que se les dio sepultura con semejantes honores de capitán general, fueron trasladados al cementerio de Paracuellos.

En el editorial de La Vanguardia Española del martes 20 de febrero se destacó que la ceremonia había sido, de manera digna a la memoria que se evocaba, un tácito juramento de guardar el legado de los «mártires que murieron por la patria haciendo imperecedera, con el recuerdo del crimen sin nombre, la voluntad tensa e irrevocable de defender a España contra todos los enemigos más o menos larvados del pensamiento y de los amores en cuyo holocausto aquellos compatriotas heroicos dieron su sangre generosa» ${ }^{38}$. Cada homenaje fúnebre en toda España era - subrayó el editorial de la edición madrileña de $A B C$ del día siguiente - una lección alentadora para alcanzar el porvenir de España. Cada fosa debía ser un ejemplo, y no un símbolo funerario ${ }^{39}$.

El recuerdo de los «caídos», que evocó el rito de culto a las víctimas enterradas en la fosa del paraje del arroyo de San José, en Paracuellos, muestra que la acción de recordar produce la memoria mediante la percepción del pasado como duración vivida ininterrumpidamente en el presente $^{40}$. La vivencia de la memoria renueva y localiza un acontecimiento como portador y símbolo de ciertas significaciones para la identidad de la comunidad en el presente. Esta dimensión identitaria de la memoria produce procesos de integración y de desintegración políticas al agrupar a los hombres como amigos y enemigos.

La extensión de este mecanismo de la memoria conllevó que se multiplicasen tales puntos centrales, sobre todo a través de los monumentos a los «caídos» en cada localidad. Pero también conllevó la focalización en un único punto espacial. Así, el Decreto de 1 de abril de 1940, de la Presidencia del Gobierno ${ }^{41}$, dispuso, con objeto de perpetuar la memoria de «los que cayeron en nuestra Cruzada», la elección como lugar para su reposo la finca situada en las vertientes de la Sierra de Guadarrama, conocida con el nombre de Cuelga-muros (a 9,5 km al norte del Monasterio de San Lorenzo de El Escorial), y declaró de urgente ejecución las obras para

38 La Vanguardia Española, 20-II-1940.

39 «El mandato de los que cayeron», ABC, Madrid, 21-II-1940.

${ }^{40} \mathrm{La}$ idea de que la virtud del rito proviene intrínsecamente de sí mismo, animado de un poder inmanente que procede de la propia naturaleza de la práctica ritual como acto tradicional eficaz, puede verse en Mauss, 1970, pp. 137-142.

41 BOE, 2-IV-1940. 
alzar una basílica, un monasterio y un cuartel de Juventudes ${ }^{42}$. La necesidad particular de este lugar de memoria respondía, según el preámbulo justificativo del Decreto, a la dimensión de la «Cruzada», la heroicidad de los sacrificios que la victoria encerraba y la trascendencia de esa epopeya para el futuro de España, que no podían quedar perpetuados por los sencillos monumentos conmemorativos alzados en villas y ciudades. Por su capacidad de rememorar la enormidad del acontecimiento de la guerra y la magnitud del sacrifico de las víctimas, se concluía:

«Es necesario que las piedras que se levanten tengan la grandeza de los monumentos antiguos, que desafíen al tiempo y al olvido y que constituyan lugar de meditación y de reposo en que las generaciones futuras rindan tributo de admiración a los que les legaron una España mejor.

A estos fines responde la elección de un lugar retirado donde se levante el templo grandioso de nuestros muertos en que por los siglos se ruegue por los que cayeron en el camino de Dios y de la Patria. Lugar perenne de peregrinación en que lo grandioso de la naturaleza ponga un digno marco al campo en que reposen los héroes y mártires de la Cruzada».

Si el general Franco como jefe del Estado encabezó la suscripción para alzar un altar en Paracuellos del Jarama, la Presidencia del Gobierno - que Francisco Franco ocupó junto a la Jefatura del Estado - impulsó este otro magno proyecto de panteón bajo su control a través del Consejo de Obras del Monumento ${ }^{43}$. Este no fue un gesto para la reconciliación, sino para la perpetuación del recuerdo de la «Cruzada» y de los «caídos» en defensa de la «causa nacional». Así, se previó el futuro traslado de los restos de víctimas no identificadas, que hubieran padecido bajo la «dominación roja», al Panteón de los Caídos. En la Orden de 4 de abril de ese año $1940^{44}$ se expuso que la diversidad de lugares donde la «saña mar-

42 Esta construcción no contó con el previo consentimiento por escrito de la correspondiente autoridad eclesiástica, según establecía preceptivamente el Código de Derecho Canónico entonces en vigor (Codex Iuris Canonici, IX, c. 1162 y sigs., en AAS, IX, pars II, p. 226 y sigs.). Sigue siendo estimable la obra de Sueiro, 1976. Véase, asimismo, Olmeda, 2009.

43 Por Decreto de julio de 1941 (BOE, 6-VIII-1941), la Presidencia del Gobierno crearía un Consejo de Obras del Monumento a los Caídos.

44 BOE, 5-IV-1940. Una nueva Orden de 11 de julio de 1946 (BOE, 15-VII-1946) prorrogó indefinidamente los enterramientos temporales de los restos de «caídos». 
xista» condujo a sus víctimas para darles muerte había motivado la existencia, en muchos términos municipales, de sitios con restos humanos que, al no ser posible su identificación, no habían sido reclamados por familiares para trasladarlos al cementerio. El debido homenaje a «nuestros mártires» exigía que, hasta que pudieran ser recogidos esos restos en el Panteón de los Caídos, se adoptasen medidas para evitar posibles profanaciones y asegurar el respeto debido.

Esta inflación del culto de los «caídos», entre otras políticas del «nuevo Estado», continuó suscitando puntualmente el malestar de la jerarquía eclesiástica en España, siendo objeto de crítica por el arzobispo de Sevilla, el cardenal Segura, en su pastoral Por los fueros de la verdad y de la justicia que se hizo pública el 15 de abril de $1940^{45}$. De los principios que decía defender, el sexto era el gustoso reconocimiento de «la significación católica del nuevo Estado», si bien había que procurar el evitar que determinadas medidas y actuaciones perjudicaran los derechos de la Iglesia y los intereses de las almas: la censura de la pastoral del Cardenal Primado Lecciones de la guerra y deberes de la paz, o los impedimentos para que la prensa sevillana publicara sus propios escritos; el acuerdo hispano-alemán; las misas de campaña, cruces y lápidas de los «caídos»; las trabas a las asociaciones profesionales católicas y la sustitución de las entidades católicas de caridad por las estatales de Auxilio Social; las «profanas novedades en el hablar», expresiones por las que «se corre el riesgo de extraviarse en la fe y en la piedad»; la circulación de doctrinas perniciosas en el cine o libros; o que los capellanes de las organizaciones juveniles no estuvieran sometidos a la jurisdicción episcopal ${ }^{46}$.

\section{El Monumento Nacional a los Caídos}

Próxima la terminación de las obras en el Valle de Cuelgamuros se creó una Fundación, que había de ejercer, bajo el patronato del Jefe del Estado, la titularidad del monumento con todos sus bienes y pertenencias. Por Decreto-Ley de 23 de agosto de 1957 se creó la Fundación de la Santa Cruz del Valle de los Caídos ${ }^{47}$. Sus fines serían rogar a Dios por las almas de los muertos en la «Cruzada Nacional», impetrar las bendiciones

\footnotetext{
45 Boletín Oficial Eclesiástico del Arzobispado de Sevilla, 15-IV-1940, pp. 262-295.

46 Ibidem, p. 280 y sigs.

47 BOE, 5-IX-1957.
} 
del Altísimo para España y laborar por el conocimiento e implantación de la paz entre los hombres sobre la base de la doctrina social cristiana. Para el cumplimiento de estos fines, el Patronato de la Fundación concertaría, con la Abadía benedictina de Silos, el establecimiento en el Valle de Cuelgamuros de una Abadía benedictina de la «Santa Cruz del Valle de los Caídos», que tendría carácter independiente. En el preámbulo de esta disposición, el significado del monumento se justificó por la fe religiosa del pueblo español, el sentido profundamente católico de la «Cruzada» y el signo social del «nuevo Estado» que nació de la guerra. El carácter cristiano del monumento perpetuaba el deber sagrado de honrar a los héroes y mártires que habían muerto en nombre de la «Cruzada de Liberación». Pero este recuerdo debía ir acompañado del perdón que impone el mensaje evangélico. Además, los lustros de paz después de la «Victoria» vieron el desarrollo de una política guiada por el más elevado sentido de unidad y hermandad entre los españoles: «Este ha de ser en consecuencia, el Monumento a todos los Caídos, sobre cuyo sacrificio triunfen los brazos pacificadores de la Cruz».

Del mismo modo, la finalización de las obras hizo que se agilizasen los trámites para el traslado de restos mortales a ese lugar. En la sesión del Consejo de las Obras del día 30 de septiembre de ese año 1957, que presidió el general Franco, se acordó, en respuesta a los escritos que había enviado la Asociación de Mártires de la provincia de Madrid, el proponer el rápido traslado de los restos mortales sepultados en Paracuellos al Monumento Nacional con el fin de evitar los gastos de obras en aquel cementerio. Asimismo, se acordó que la Guardia Civil hiciera relaciones de los muertos y asesinados en las distintas localidades y un informe sobre los deseos de los familiares acerca del traslado de dichos restos ${ }^{48}$. Para su cumplimiento, el entonces ministro de la Gobernación, el general de brigada Camilo Alonso Vega, dirigió una circular a los gobernadores civiles en mayo de 1958, ordenando que remitieran al Consejo de Obras del Monumento Nacional a los Caídos, en un plazo no superior a 30 días, una relación de los enterramientos colectivos que existiesen en sus provincias, tanto «de caídos en los frentes de batalla o sacrificados por la Patria». Para recabar la información, pedirían la colaboración de los alcaldes, la Guardia Civil, los párrocos y las autoridades locales. En el mismo plazo, enviarían otra relación de personas enterradas en cementerios católicos,

48 AGA, Sección Gobernación (SG), c. 12144.

Historia Contemporánea 55: 609-635 
iglesias o panteones privados, precisando que el listado sería de «quienes cayeron en nuestra Cruzada, sin distinción del campo en que combatieran», siempre y cuando fueran de nacionalidad española y religión católica, y que los parientes más próximos debían dar el permiso ${ }^{49}$. Sin embargo el plazo que se había dado a las autoridades, se acordó ampliarlo en la sesión del 25 de junio del Consejo de Obras ${ }^{50}$.

La atención a los asuntos del traslado de los restos de los «caídos»al Valle de Cuelgamuros justificó que se acordara, en el Consejo de Ministros del 10 de octubre de ese año, constituir una Comisión, que presidió el ministro subsecretario de la Presidencia ${ }^{51}$. En una nueva circular del Ministerio de la Gobernación a los gobernadores civiles del 31 de ese mismo mes, se informó de las primeras decisiones de la Comisión y se encarecía a que, antes del 20 de noviembre, se enviara a la Subsecretaría del Ministerio un informe en el que se precisaran: a) el número de enterrados en cementerios parroquiales, iglesias, panteones, que estuvieran identificados y se tuviese la conformidad familiar, pudiéndose recoger sus restos en caja individual; b) el número de enterrados igualmente en cementerios parroquiales, iglesias o panteones, no identificados o que, aun identificados, por estar en fosa común o por otras circunstancias, no pudieran ser individualizados sus restos, que serían depositados en cajas colectivas; c) el número de enterrados en cementerios especiales, de caídos en el frente o inmolados, que estuviesen identificados y se supusiera que sus restos podían recogerse en caja individual, si bien no se incluían los cementerios de extranjeros; y d) el número de enterrados también en los cementerios especiales que, no estando identificados o que, aun estándolo, por estar en fosa común o por otras circunstancias, sus restos no podían ser individualizados, por lo que habrían de trasladarse en cajas colectivas. Por otra parte, cada uno de los Gobiernos Civiles debía determinar, sobre un mapa de $60 \times 60 \mathrm{~cm}$ de sus provincias respectivas, las localidades en las que existían «caídos» o «inmolados» a trasladar y, al margen del nombre de cada localidad, se anotaría, en tinta negra, el número total de restos en cajas individuales y, en tinta roja, el número de cajas colectivas. Asimismo, se confeccionaría una relación de localidades, indicando para cada una, en cuatro columnas, la suma total para cada uno de los cuatro casos de restos a trasladar. Siempre antes del 1 de febrero de 1959, cada gobernador civil

\footnotetext{
49 AGA, SG, c. 12144.

50 AGA. SG, c. 12144.

51 AGA, SG, c. 12144.
} 


\section{Cuadro 1}

Datos por provincias del traslado de restos mortales al Valle de los Caídos

\begin{tabular}{|c|c|c|c|c|c|}
\hline Provincia & $\begin{array}{l}\text { Apartado } \\
\text { a) }\end{array}$ & $\begin{array}{l}\text { Apartado } \\
\text { b) }\end{array}$ & $\begin{array}{l}\text { Apartado } \\
\text { c) }\end{array}$ & $\begin{array}{l}\text { Apartado } \\
\text { d) }\end{array}$ & Total \\
\hline Álava & 96 & 117 & - & - & 213 \\
\hline Albacete & 21 & 12 aprox. & - & - & 33 aprox. \\
\hline Alicante & 11 & - & - & - & 11 \\
\hline Almería & 18 & - & - & - & 18 \\
\hline Ávila & 17 & 31 & - & 40 & 88 \\
\hline Badajoz & 45 & 1.243 aprox. & 4 & 68 & 1.360 aprox. \\
\hline Baleares & 18 & - & - & - & 18 \\
\hline Barcelona & 36 & - & 125 & 24 & 185 \\
\hline Burgos & 7 & 37 aprox. & 10 & 15 aprox. & 69 \\
\hline Cáceres & 32 & 99 & - & 9 & 140 \\
\hline Cádiz & 6 & 109 aprox. & - & - & 115 aprox. \\
\hline Castellón & 43 & 1.696 & - & - & 1.739 \\
\hline Ciudad Real & 27 & 19 & - & - & 46 \\
\hline Córdoba & 63 & 51 & - & - & 114 \\
\hline Coruña & - & - & - & - & - \\
\hline Cuenca & 3 & 7 & - & - & 10 \\
\hline Gerona & 11 & 149 & 1 & 115 aprox. & 276 aprox. \\
\hline Granada & 102 & 90 & 14 & 49 & 255 \\
\hline Guipúzcoa & 18 & 14 & - & - & 32 \\
\hline Guadalajara & 13 & 15 & 4 & - & 32 \\
\hline Huelva & 6 & - & - & - & 6 \\
\hline Huesca & 5 & 3 & 80 & 434 & 522 (532 or.) \\
\hline Jaén & 16 & 21 & - & - & 37 \\
\hline Las Palmas & - & - & - & - & - \\
\hline León & 4 & 7 & - & - & 11 \\
\hline Lérida & 2 & 2 & - & - & 4 \\
\hline Logroño & 5 & - & 1 & 4 & 10 \\
\hline Lugo & 12 & - & - & - & 12 \\
\hline Madrid & 667 & 1.971 aprox. & 27 & 1.7176 & 1.9841 aprox. \\
\hline Málaga & 29 & 1.622 aprox. & 7 & 50 aprox. & 1.708 aprox. \\
\hline Murcia & 4 & 39 & - & - & 43 \\
\hline Navarra & 4 & - & - & - & 4 \\
\hline Orense & 1 & - & - & - & 1 \\
\hline Oviedo & 54 & 1.571 & 551 & 20 & 2.196 \\
\hline Palencia & 23 & - & - & - & 23 \\
\hline Pontevedra & 8 & 3 & 21 & 101 & 133 \\
\hline Salamanca & 6 & - & - & - & 6 \\
\hline
\end{tabular}




\begin{tabular}{lccccc}
\hline \multicolumn{1}{c}{ Provincia } & $\begin{array}{c}\text { Apartado } \\
\text { a) }\end{array}$ & $\begin{array}{c}\text { Apartado } \\
\text { b) }\end{array}$ & $\begin{array}{c}\text { Apartado } \\
\text { c) }\end{array}$ & $\begin{array}{c}\text { Apartado } \\
\text { d) }\end{array}$ & Total \\
\hline Sta. Cruz de Tenerife & - & - & - & - & - \\
Santander & 27 & - & 65 & 18 aprox. & 110 aprox. \\
Segovia & 61 & 385 & 2 & 41 & 489 \\
Sevilla & 14 & 4 & - & - & 18 \\
Soria & 3 & - & - & - & 3 \\
Tarragona & 49 & 1.336 & 2.755 & 1.782 & 5.922 \\
Teruel & 72 & 4.137 & - & 381 & 4.590 \\
Toledo & 34 & 102 & 11 & 3 & 150 \\
Valencia & 44 & 717 & 4 & 20 & 785 \\
Valladolid & 39 & - & - & - & 39 \\
Vizcaya & 31 & 258 aprox. & - & 84 aprox. & 373 aprox.* \\
Zamora & 4 & 4 & - & - & 8 \\
Zaragoza & 200 & 3.230 & - & - & 3.430 \\
\hline & 2.011 & 19.101 & 3.682 & 20.434 & 45.228 \\
\hline a) y c) & 5.693 & d) y d) & & 39.535 & \\
\hline
\end{tabular}

* La cifra en el documento original es de 273 cadáveres aproximadamente.

Fuente: AGA, SG, c. 12144. Elaboración propia.

decidiría el plazo en que podrían estar todos los restos mortales en las correspondientes cajas; los lugares de reunión de las mismas, que podía hacerse en determinadas localidades hasta completar la capacidad de uno o más camiones, y el itinerario y el tiempo a emplear por los camiones que se enviaran desde Madrid para recoger las cajas mortuorias ${ }^{52}$.

En un primer resumen de los datos que resultaban de los informes enviados hasta el 13 de enero de ese año 1959 a los gobernadores civiles, los restos mortales que se trasladarían al Valle de los Caídos en cajas individuales (casos a y c de la circular de 31 de octubre de 1958) ascendían a 2.494, y a 32.001 los que deberían serlo en cajas colectivas (casos b y d). En una segunda relación complementaria con datos de las provincias no

52 AGA, SG, c. 12144. En la circular número 2 del año 1959, del Ministerio de la Gobernación, con fecha de 13 de febrero, se precisaron más instrucciones a los gobernadores civiles sobre el traslado de restos mortales al Valle de los Caídos, acompañándose adjuntos los diseños de las cajas que debían contener los restos individuales y colectivos, y el pliego de condiciones para la construcción de las mismas. 
incluidas en el primer informe, de fecha del 23 de febrero, se indicó que los restos que se trasladarían en cajas individuales eran 3.182 más (casos a y c) y 7.550 - más un numero indeterminado - los cadáveres que serían trasladados en cajas colectivas (casos b y d) ${ }^{53}$. Entre ambos listados, figuraba que serían unos 5.676 y 39.551 el total de restos mortales en cajas individuales y cajas colectivas que se trasladarían al Valle de los Caídos; es decir, unos 45.228 cadáveres.

La mayor parte de los retos mortales no estaban identificados y fueron exhumados de fosas comunes, sobre todo en cementerios especiales donde habían sido enterrados combatientes en los frentes de batalla durante el transcurso de la guerra civil. De ahí que fueran más los cadáveres desenterrados en las provincias de Badajoz, Oviedo, Málaga, Teruel o Tarragona y Zaragoza, escenario éstas de la batalla del Ebro. Pero fue sobre todo en Madrid donde se recuperó la mayor parte de restos mortales para su traslado al Valle de los Caídos (casi un $44 \%$ del total), siendo exhumados en gran medida del cementerio de Paracuellos del Jarama. El traslado de los restos mortales comenzaría el 19 de marzo de aquel año 1959 y, a fecha del día 31 de ese mes, se habrían depositado 5.041 restos; de ellos, 1.041 en cajas individuales y el resto en cajas colectivas. Tras el día 1 de abril, continuaría el traslado de restos, especialmente de los procedentes de la provincia de Madrid. En esta misma circular, con indicaciones sobre el acto inaugural del Valle de los Caídos, se estableció que, una vez que los hermanos de José Antonio Primo de Rivera habían dado la conformidad, sus restos mortales serían trasladados el 30 de marzo a las 9 horas de la mañana desde El Escorial, asistiendo todos los jefes provinciales de FET y de las JONS y algún delegado de servicio de cada provincia. Los restos mortales de José Antonio serían llevados desde la basílica escurialense en andas a lo largo de dos kilómetros y en sucesivos turnos. Luego, un furgón los trasladaría hasta dos kilómetros de la basílica del Valle de los Caídos, para volver a ser llevados en andas por turnos ${ }^{54}$.

La inauguración del monumento ocurrió el 1 de abril de 1959, en el vigésimo aniversario del final de la guerra civil. El acto ceremonial, tras la llegada del general Franco a la explanada de la basílica, fue retransmitido por TVE y por los equipos de Radio Nacional. El jefe del Estado, Francisco Franco, fue recibido a la entrada de la cripta por la comuni-

\footnotetext{
53 AGA, SG, c. 12144.

54 AGA, SG, c. 12144.
} 
dad benedictina del monasterio del Valle de los Caídos, con su abad mitrado al frente, fray Justo Pérez de Urbel, que le ofreció agua bendita y le dio a besar el Lignum Crucis. Seguidamente, bajo palio, y a los acordes del himno nacional, entró en la cripta acompañado por su esposa, Carmen Polo. El funeral fue oficiado en el interior de la basílica por el cardenal primado Pla y Deniel. Tras finalizar el acto litúrgico, y salir del recinto de la cripta bajo palio, el general Franco se dirigió al templete instalado en la explanada de la basílica para pronunciar un discurso ante una explanada concurrida de excombatientes.

Esencialmente, las palabras de Franco fueron que, en el origen, ocurrió la guerra contra el enemigo de España. Veinte años después se volvía a reactualizar un acontecimiento "sagrado», que tuvo lugar en un pasado «mítico». El acontecimiento de la guerra de España conservaba el mismo sentido original, como Franco remarcó en su discurso. La guerra no fue una mera contienda civil, sino «una verdadera Cruzada», que había adquirido la dimensión de una epopeya que trajo la mayor y más trascendente independencia contra la «anti-España». La reactualización de aquel conflicto se imponía en el presente, pues el enemigo continuaba al acecho, sobre todo envenenando y avivando la curiosidad y el afán de novedades de la juventud:

«Mucho fue lo que a España costó aquella gloriosa epopeya de nuestra liberación para que pueda ser olvidado; pero la lucha del bien y del mal no termina por grande que sea su victoria. Sería pueril creer que el diablo se someta, inventará nuevas tretas y disfraces, ya que su espíritu seguirá maquinando y tomará formas nuevas de acuerdo con los tiempos.

La anti-España fue vencida, y derrotada, pero no está muerta. Periódicamente la vemos levantar cabeza en el exterior y en su soberbia y ceguera pretender envenenar y avivar de nuevo la innata curiosidad y el afán de novedades de la juventud. Por ello es necesario cerrar el cuadro contra el desvío de los malos educadores de las nuevas generaciones».

La unidad que trajera la victoria en la guerra había que mantenerla, pues la victoria no se había administrado a favor de un grupo ni de una clase, sino en el de toda la nación. No cabía el descanso y no podían desmovilizarse los espíritus después de la batalla. La tensión del «Movimiento» político era necesaria para mantener el «fuego sagrado» de la defensa de aquellos principios que eran comunes. Franco acabó haciendo un llamamiento a mantener la hermandad original forjada en las filas de la 
«Cruzada»; a evitar que el enemigo, siempre al acecho, pudiera infiltrase; y a inculcar en los hijos y a proyectar en las generaciones venideras la razón permanente del $\ll$ Movimiento» ${ }^{55}$.

\section{Conclusión}

La defensa de la integridad y de la supremacía de la esfera católica en sus competencias durante la posguerra, sobre todo ante el discurso hegemónico y las políticas falangistas (que aspiraron a imponer los valores, las creencias e ideas del nacional-sindicalismo en la dirección del «nuevo Estado» como instrumento totalitario al servicio de la patria), muestra que el ritual político de culto a los «caídos» no sólo sirvió a las estrategias de integración, sino que de manera ambivalente también permitió el uso de estrategias simbólicas diferenciadas para asegurar o alcanzar el poder en un marco específico de oportunidad política dentro del régimen dictatorial ${ }^{56}$. La sesgada apropiación falangista del culto de los «caídos» no sólo continuó la parafernalia ceremonial anterior de Falange Española y de las JONS en el homenaje a sus militantes muertos, sino que situó el origen de la «nueva España» y estableció el sentido del sacrificio colectivo de la guerra en un tiempo sagrado, primordial: la fundación del partido falangista en el acto celebrado en el Teatro de la Comedia, en Madrid, por José Antonio Primo de Rivera el 29 de octubre de 1933. Su figura fue santificada y ocupó el centro del culto de los mártires por la patria desde 1938. La transferencia de la idea de carisma desde su origen en la experiencia religiosa a la exaltación del «Ausente» fue un elemento principal en la sacralización de la política ${ }^{57}$.

55 Sobre la «construcción de la memoria» en relación con las identidades colectivas en España desde la guerra civil, véase Richards, 2015 (ed. or. en inglés de 2013).

56 Se trata de lo que Lukes llamó «movilización de inclinaciones» (mobilization of bias); es decir, de un conjunto de valores predominantes, creencias, rituales y procedimientos constituyentes que operan de manera sistemática y consistentemente en beneficio propio o para su hegemonía, pero que no suponen un desafío al orden social y político existente. Véase Lukes, 1975, pp. 289-308.

57 El politólogo italiano E. Gentile afirmó que el fascismo poseyó desde sus orígenes las características de una religión secular; véase Gentile, 1990 (hay traducción catalana en Gentile, 1996, pp. 545-565 y al español en Gentile, 2006, pp. 219-245) y Gentile, 1993. Sobre la reproducción y transformación de ciertas tradiciones cristianas dentro del nazismo, véase Steigmann-Gall, 2007 (ed. or. en inglés de 2003). Acerca de la noción de «religión política»y los debates que ha suscitado, véase Box, 2006. 
De esta manera, se fueron introduciendo conceptos político-teológicos en la cultura de guerra, cuya retórica y rituales provocaron la reacción de la Iglesia católica en la España de posguerra.

Aunque a lo largo de los sucesivos jalones en la institucionalización de la dictadura se mantuvo incólume el recuerdo oficial de la guerra como origen de la redención de España, fue produciéndose un proceso de creciente rutinarismo ceremonial, que fue desactivando el potencial hegemónico del falangismo como proyecto ideológico. La exacerbación del sentir nacionalista fue el vector que transfirió la sacralidad a la política del «nuevo Estado». El culto de la nación se reveló como una experiencia colectiva de religación con lo sagrado a través de rituales públicos y liturgias políticas. La nación española, encarnada en la figura carismática de su «Caudillo» Francisco Franco, y santificada con la sangre del sacrificio de los «caídos» por la patria, aparece transfigurada en una entidad espiritual.

En ese proceso, el acto ceremonial de inauguración del Valle de los Caídos renovó este significado plenamente. Sin embargo, hay que destacar una novedad al respecto conforme se manifestó en el discurso legal y político: si la redención de penas había sido el centro de la política penitenciaria del «nuevo Estado» en sus inicios, aparece ahora el acto del perdón de los culpables como imperativo moral cristiano. Por otra parte, si la guerra fue un punto de ruptura con un presente degradado y de decadencia nacional durante el período republicano, su vigencia como origen de una «nueva España» debía ser renovada en la memoria colectiva de la generación más joven que no había vivido aquella realidad traumática. Después de veinte años, la creciente brecha generacional que se iba abriendo debía ser cerrada, promoviéndose la «memoria cultural» común de aquel pasado. La memoria cultural permanece arraigada en lo originario, que es un punto fijo en el pasado; un horizonte temporal que no se desvanece con el paso del tiempo. Como institución, la memoria cultural preserva la identidad común y se materializa simbólicamente en «signos de la memoria»: textos, imágenes, ritos y monumentos. Como parteaguas, la inauguración del monumento nacional del Valle de los Caídos reconstruyó aquel legado y cristalizó su significado en la España de principios de 1959: la guerra de 1936 como acontecimiento fundacional. Desde entonces, el lugar del Valle de los Caídos ha ido polarizando adhesiones y rechazos en torno a la memoria cultural del pasado reciente de España. 


\section{Fuentes documentales}

Archivo General de la Administración, Alcalá de Henares.

SeCCIÓN DE CULTURA, Ministerio de Información y Turismo, caja 1364 y 1378.

SECCIÓN GOBERNACIÓn, caja 12144.

Archivo Histórico Nacional, Madrid.

Fondos Contemporáneos, Causa General, Pieza especial de Madrid sobre

Exhumaciones de Mártires de la Cruzada, legajo 1536, exp. 2.

\section{Fuentes legislativas impresas}

acta Apostolicae Sedis. Comentarium Officiale, Typis Polyglottis Vaticanis, Romae.

ACTAS DE LAS CONFERENCIAS DE METROPOLITANOS ESPAÑOLES (1921-1965), edición de Vicente Cárcel Ortí, BAC, Madrid, 1994.

BOLETIN OFICIAL DEL ESTADO.

BoLETÍN OFICIAL ECLESIÁSTICO DEL ARZOBISPADO DE SEVILLA.

BOLETÍN OFICIAL ECLESIÁSTICO DEL ARZOBISPADO DE TOLEDO.

\section{Fuentes hemerográficas}

$A B C$, Madrid.

ARRIBA, Órgano de Falange Española Tradicionalista y de las J.O.N.S. de Madrid

LA VANGUARDIA ESPAÑOLA, Barcelona.

\section{Bibliografía}

AssmanN, Jan, «Das kollektive Gedächtnis zwischen Körper und Scrift: zur Gedäftnisteorie von Maurice Halbwachs», en KRAPOTH, Hermann y LABORDE, Denis (eds.), Erinnerung und Gesellschaft/Mémoire et société: Hommenage à Maurice Halbwachs (1877-1945), VS Verlag, Wiesbaden, 2005, pp. 6583.

Assmann, Jan, Das kulturelle Gedächtnis: Schrift, Erinnerung und politische Identität in frühen Hochkulturen, Beck, München, 1992.

BECKER, Annette, La guerre et la foi. De la mort á la memoire 1914-1930, Armand Colin, Paris, 1994. 
BeCKer, Annette y Audoin-RouzeAu, Stéphane, «Vers une histoire culturelle de la Première Guerre mondiale», Vingtième siècle. Revue d'histoire, n. ${ }^{\circ} 41$ (jan.-mars 1994), pp. 5-7.

Becker, Annette y Audoin-Rouzeau, Stéphane, «Violence et consentement: la «culture de guerre» du premier conflit mondial», en RIOUX, Jean-Pierre y Sirinelli, Jean-François (dirs.), Pour une histoire culturelle, Seuil, Paris, 1997, pp. 251-271.

Becker, Annette y Audoin-Rouzeau, Stéphane, 14-18, retrouver la Guerre, Gallimard, París, 2000.

Box, Zira, «Pasión, muerte y glorificación de José Antonio Primo de Rivera», Historia del Presente, n. ${ }^{\circ} 6$ (2005), pp. 191-218.

Box, Zira, «La tesis de la religión política y sus críticos: aproximación a un debate actual», Ayer, n. ${ }^{\circ} 62$ (2006), pp. 195-230.

Box, Zira, «Rituales funerarios. Culto a los caídos y política en la España franquista: a propósito de los traslados de José Antonio Primo de Rivera (19391959)», en CASQuete, Jesús y CRuz, Rafael (eds.), Políticas de la muerte. Usos y abusos del ritual fúnebre en la Europa del siglo XX, Los libros de la Catarata, Madrid, 2009, pp. 265-298.

CANNADINE, David, «War and death, grief and mourning in Modern Britain», en Whaley, Joachim (ed.), Mirrors of Mortality: Studies in the Social History of Death, Europa Publications, London, 1981, pp. 187-242.

Di FEBo, Giuliana, «I riti del nazionalcattolicesimo nella Spagna franchista. José Antonio Primo de Rivera e il culto dei caduti (1936-1960)», en RIDOLFI, Maurizio (a cura di), Rituali civili. Storie nazionali e memorie pubbliche nell'Europa contemporanea, Gangemi, Roma, 2006, pp. 189-202.

Dionisio VIVAS, Miguel Ángel, «La prohibición de la carta pastoral «Lecciones de la guerra y deberes de la paz» y los conflictos entre la Iglesia y el Gobierno español en el otoño de 1939», Toledana: cuestiones de teología e historia, n. 20 (2009), pp. 81-108.

Dionisio Vivas, Miguel Ángel, Por Dios y la Patria: el cardenal Gomá y la construcción de la España nacional, Instituto Superior de Estudios Teológicos San Ildefonso, Toledo, 2015.

GENTILE, Emilio, «Fascism as Political Religion», Journal of Contemporany History, Vol. 25, No. 2/3 (May-Jun., 1990), pp. 229-251 (hay traducción catalana: «El feixisme com a religió política», Afers, XI, n. 25 (1996), pp. 545565.

GentiLE, Emilio, Il culto del littorio. La sacralizzazione della politica nell'Italia fascista, Laterza, Roma, 1993.

GENTILE, Emilio, Fascismo. Historia e interpretación, Alianza Editorial, Madrid 2004.

Goma Y TomÁs, Isidro, Por Dios y por España, Rafael Casulleras, Barcelona, 1940.

Historia Contemporánea 55: 609-635 
González Calleja, Eduardo y Sevillano Calero, Francisco, «Crociati moderni: dal lessico politico republicano alla propaganda franchista nella guerra spagnola», Memoria e Ricerca. Rivista di storia contemporanea, Anno XI, Nuova Serie, n. ${ }^{\circ} 13$ (maggio-agosto 2003), pp. 89-113.

GORER, Geofrey, «The Pornography of Death», Encounter, October 1955, pp. 4952.

Granados, Anastasio, El Cardenal Gomá, Primado de España, Espasa Calpe, Madrid, 1969.

Gregory, Adrian, The Silence of Memory. Armistice Day 1919-1946, Berg, Oxford/Providence, 1994.

Hubert, Henri y Mauss, Marcel, «Essai sur la nature et la fonction de sacrifice», L'Année Sociologique, Année 2 (1897-1898), pp. 29-138.

Kantorowicz, Ernst H., «Pro Patria Mori in Medieval Political Thought», The American Historical Review, Vol. 56, No. 3 (Apr., 1951), pp. 472-492.

LAzo, Alfonso, La Iglesia, la Falange y el fascismo (Un estudio sobre la prensa española de posguerra), Secretariado de Publicaciones de la Universidad de Sevilla, Sevilla, 1995.

Lazo, Alfonso, Una familia mal avenida. Falange, Iglesia, Ejército, Síntesis, Madrid, 2008.

LEDESMA, José L. y RodRIGO, Javier, «Caídos por España, mártires de la libertad. Víctimas y conmemoración de la Guerra Civil en la España posbélica (19392006)», Ayer, n..$^{\circ} 63$ (2006), pp. 233-255.

LUKES, Steven, «Political Ritual and Social Integration», Journal of the British Sociological Association, IX, No. 2 (1975), pp. 289-308.

Mauss, Marcel, Lo sagrado y lo profano. Obras I, Barral Editores, Barcelona, 1970.

Mosse, George L., Fallen Soldiers: Reshaping the Memory of the World Wars, Oxford University Press, Oxford, 1991 (trad. esp.: Soldados caídos. La transformación de la memoria de las guerras mundiales, PUZ, Zaragoza, 2016).

Nora, Pierre, «Entre Mémoire et Histoire. La problématique des lieux», en NorA, Pierre (dir.), Les lieux de mémoire, Gallimard, Paris, 1997, vol. 1, pp. 23-43.

Olmeda, Fernando, El Valle de los Caídos. Una memoria de España, Península, Barcelona, 2009.

RICHARDS, Michel, Historias para después de una guerra. Memoria, política y cambio social en España desde 1936, Pasado \& Presente, Barcelona, 2015.

RodríGuez AISA, M. ${ }^{a}$ Luisa, El Cardenal Gomá y la guerra de España, CSIC, Madrid, 1981.

SHERman, Daniel J., The Construction of Memory in Interwar France, University of Chicago Press, Chicago, 1999.

Steigmann-Gall, Richard, El Reich sagrado. Concepciones nazis sobre el cristianismo, 1919-1945, Akal, Madrid, 2007. 
SuEIRo, Daniel, La verdadera historia del Valle de los Caídos, SEDMAY ediciones, Madrid, 1976.

WinTER, Jay, Sites of Memory, Sites of Mourning. The Great War in European cultural history, Cambridge University Press, Cambridge, 1995.

WINTER, Jay y SiVAN, Emmanuel (eds.), War and Remembrance in the Twentieth Century, Cambridge University Press, Cambridge, 1999.

\section{Datos del autor}

Francisco Sevillano-Calero es Profesor Titular de Universidad de Historia Contemporánea. Entre los diversos artículos y estudios sobre la guerra civil y la dictadura franquista, los libros publicados son: La Guerra Civil en Albacete: rebelión militar y Justicia Popular (1936-1939). Alicante, Generalitat Valenciana/Institut de Cultura «Juan Gil-Albert», 1995. Propaganda y medios de comunicación en el franquismo (1936-1951). Alicante, Publicaciones de la Universidad de Alicante, 1998. Ecos de papel. La opinión de los españoles en la época de Franco. Madrid, Biblioteca Nueva, 2000. Exterminio. El terror con Franco, Madrid, Oberon (Grupo Anaya, S.A.), 2004. Rojos. La representación del enemigo en la guerra civil, Madrid, Alianza Editorial, 2007. Franco. Caudillo por la gracia de Dios, Madrid, Alianza Editorial, 2010. 